Int. J. Electrochem. Sci., 16 (2021) Article ID: 210262

International Journal of

ELECTROCHEMICAL

SCIENCE

wWw.electrochemsci.org

\title{
A Miniaturized Electrochemical Biosensor Based on Poly $(L$ - threonine) Modified Pencil Graphite Electrodes and Its Application for Trace-Level Determination of Uric Acid, Xanthine and Hypoxanthine
}

\author{
Zhengcai Guo, Guiyan Wang, Jinlian Li, Dongmei Wu* and Xiaoling Guo* \\ College of Pharmacy, Jiamusi University, Jiamusi, 154000, China. \\ "E-mail: guoxiaoling2004@126.com (X. Guo), dmwu@jmsu.edu.cn (D. Wu)
}

doi: $10.20964 / 2021.01 .05$

Received: 21 November 2019 / Accepted: 14 September 2020 / Published: 31 December 2020

\begin{abstract}
A miniaturized and simple analysis tool is of vital importance for practical applications in bioanalysis. This paper describes a new strategy for the trace determination of uric acid (UA), xanthine (XA) and hypoxanthine (HX) by using miniaturized electrochemical biosensor containing a disposable pencil graphite work electrode modified with poly( $L$-threonine). The novel electrochemical device set the electrochemical detection in a 96 well plates with the microliter level of sample. Cyclic voltammetry and scanning electron microscopes were employed to characterize the biosensor. Some experimental variables of the electrode measurement parameters were optimized. Electrochemical behaviors of UA, $\mathrm{XA}$ and HX on the miniaturized biosensor were studied by cyclic voltammetry. The results show that the biosensor exhibited excellent electrocatalytic activity towards the oxidation of three analytes with good reproducibility, stability and wide linear region. Meanwhile, their oxidation currents linearly increase with increasing the mixture concentration from 0.500 to $100 \mu \mathrm{M}$ for $\mathrm{HX}$ and 0.100 to $90.0 \mu \mathrm{M}$ for both UA and XA with the lowest detection limit $0.50,0.10$ and $0.100 \mu \mathrm{M}$, respectively $(\mathrm{S} / \mathrm{N}=3)$. The miniaturized electrochemical biosensor featured easily available, low-cost material and simple fabrication, which could be applied in the trace determination of practical sample.
\end{abstract}

Keywords: Miniaturized electrochemical biosensor, Pencil graphite electrodes, Uric acid, Xanthine, Hypoxanthine

\section{$\underline{\text { FULL TEXT }}$}

(C) 2021 The Authors. Published by ESG (www.electrochemsci.org). This article is an open access article distributed under the terms and conditions of the Creative Commons Attribution license (http://creativecommons.org/licenses/by/4.0/). 